GRASAS Y ACEITES 70 (4)

October-December 2019, e329

ISSN-L: 0017-3495

https://doi.org/10.3989/gya.1166182

\title{
Characterization of different ozonized sunflower oils I. Chemical changes during ozonization
}

\author{
O.E. Ledea-Lozano ${ }^{a}$, L.A. Fernández-García ${ }^{a}$, D. Gil-Ibarra ${ }^{a}$, N. Tena ${ }^{\text {, }}$, \\ R. Garcés ${ }^{\mathrm{b}}$, E. Martínez-Force ${ }^{\mathrm{b}}$ and J.J. Salas ${ }^{\mathrm{b}, \mathbb{}}$ \\ ${ }^{a}$ CNIC Ave 25 y 158 N0 15202. Cubanacan, Playa. Apartado Postal 6414, Ciudad de la Habana, Cuba.CP:12100. \\ ${ }^{\mathrm{b}}$ Instituto de la Grasa, CSIC. Ctra. Utrera Km 1, 41013, Sevilla, Spain. \\ Corresponding author: jjsalas@ig.csic.es
}

Submitted: 06 November 2018; Accepted: 22 January 2019; Published online: 22 July 2019

SUMMARY: Vegetable oils are usually rich in unsaturated fatty acids which are susceptible to oxidation. The oxidation of vegetable oils has been one of the most widely studied fields within lipid chemistry, because it alters their properties and nutritive value, inducing the formation of harmful compounds and off-flavors. Moreover, oxidized vegetable oils display altered physical and chemical properties which are conferred by the newer oxygenated compounds they contain. This is the case of ozonized oils. Ozone is a powerful oxidizing agent that mainly acts on olefinic compounds which generate ozonides and other peroxidic species that can decompose into carbonilic fragments. The action of the oxidant and the later reactions depend on the chemical environment of the reaction as well as the carbonyl termination products resulting from peroxide cleavage. In recent years, sunflower oils with different fatty acid compositions have been developed by breeding and mutagenesis. They displayed higher contents of oleic, stearic or palmitic acids, which mainly alters their triacylglycerol composition. Therefore, four different sunflower oils, common, high oleic, high stearic-high oleic and high palmitic-high oleic, were oxidized with ozone and the progress of the reaction was monitored by measuring the level of oil peroxygenation and the changes in the oils' fatty acid compositions. The peroxidated species formed during ozonation were studied by FT-IR spectroscopy. The main conclusions of this work were that ozonation caused linear oxidation rates that were similar in all the oils assayed. The addition of water accelerated oxidation, which tended to occur in linoleic polyunsaturated fatty acid The FT-IR pointed to the presence of ozonide-derived peroxides as the major oxygenated species.

KEYWORDS: Carbonyls; Fatty acids; FT-IR; Kinetics; Mutant sunflower oil; Oxidation; Ozone; Peroxides

RESUMEN: Caracterización de diferentes aceites de girasol ozonizados I. Cambios químicos durante la ozonización. Los aceites vegetales son generalmente ricos en ácidos grasos insaturados susceptibles de oxidación. La oxidación de aceites vegetales ha sido un campo de estudio intensivo dentro de la química de lípidos ya que este proceso altera sus propiedades y valor nutritivo, induciendo la formación de compuestos perjudiciales y olores y sabores indeseados. Además, los aceites vegetales oxidados muestran propiedades físicas alteradas conferidas por los nuevos compuestos oxigenados que contienen. Este es el caso de los aceites ozonizados. El ozono es un agente oxidante enérgico que actúa sobre los compuestos olefínicos generando ozónidos y otras especies peroxídicas que se descomponen en fragmentos carbonílicos. La acción del oxidante y las reacciones posteriores dependen del entorno químico de la reacción además de los productos carbonílicos de terminación resultante de la rotura de los peróxidos. El aceite de girasol común es rico en oleico y linoleico, susceptibles de ataque oxidativo por parte del ozono. En los últimos años, aceites de girasol con composiciones diferentes de ácidos grasos se han desarrollado por selección y mutagénesis. Estos aceites muestran altos contenidos en oleico, esteárico o palmítico, los cuales alteran de manera importante su composición de triglicéridos. Este trabajo es el primero 


\begin{abstract}
de una serie de dos en los cuales se estudian los cambios físico-químicos que dichos aceites de girasol experimentan durante la ozonización. Así, se oxidaron con ozono cuatro aceites de girasol diferentes, girasol común, alto oleico, alto esteárico-alto oleico y alto palmítico-alto oleico. Se monitorizaron las cantidades absorbidas de ozono, los niveles de peroxidación y los ácidos grasos que experimentaron oxidación. Las especies formadas en el proceso se estudiaron mediante espectroscopía FT-IR. El modo en que la composición de ácidos grasos del aceite afectó a las cinéticas de oxidación y los productos resultantes se comentaron a la vista de los resultados.
\end{abstract}

PALABRAS CLAVE: Aceite de mutante de girasol; Ácidos grasos; Carbonilos; Cinética; FT-IR; Oxidación; Ozono; Peróxidos

ORCID ID: Ledea-Lozano OE https://orcid.org/0000-0001-8521-2747, Fernández-García LA https://orcid.org/00000002-1043-5505, Gil-Ibarra D https://orcid.org/0000-0002-1561-6495, Tena N https://orcid.org/0000-0003-0933-5192, Garcés R https://orcid.org/0000-0003-2571-8644, Martínez-Force E https://orcid.org/0000-0001-5324-9537, Salas JJ https://orcid.org/0000-0002-3259-2587

Citation/Cómo citar este artículo: Ledea-Lozano OE, Fernández-García LA, Gil-Ibarra D, Tena N, Garcés R, Martínez-Force E, Salas JJ. 2019. Characterization of different ozonized sunflower oils I. Chemical changes during ozonization. Grasas Aceites 70 (4), e329. https://doi.org/10.3989/gya.1166182

Copyright: (C2019 CSIC. This is an open-access article distributed under the terms of the Creative Commons Attribution 4.0 International (CC BY 4.0) License.

\section{INTRODUCTION}

Vegetable seeds oils consist of a matrix of triacylglycerols (TAGs) plus minor components which could include a broad variety of compounds including sterols, triterpenic alcohols, tocopherols and pigments (Gunstone, 2011). The physicochemical properties of oils are mainly determined by the fatty acids esterified to the glycerol backbone. Commercial seed oils display a limited variety of fatty acids. Thus, the main acyl components of these oils are C18 unsaturated fatty acids such as oleic, linoleic or linolenic acids. The saturated fatty acids palmitic and stearic are also common components of these oils, although in lower proportions, as it happens with some C20 and C22 saturated or unsaturated species. Sunflower oil is one of the most appreciated seed oils due its light flavor, pale color and balanced composition of fatty acids (Salas et al., 2015). The major fatty acids present in common sunflower oil are oleic and linoleic, which are found in different proportions depending mainly on the temperature during seed filling and maturation. Palmitic and stearic acids are present in proportions lower than $10 \%$, and low proportions of arachidic and behenic (less than $2 \%$ ) are also detected. Trace amounts $(<0.5 \%)$ of linolenic and lignoceric acids have been reported as well (Gunstone, 2011). Sunflower oil is widely sold commercially for frying throughout the world. In this regard, oxidation is the alteration that sunflower oil most often undergoes (Crapiste et al., 1999). The oxidation of vegetable oil is usually mediated by the process called autoxidation (Frankel, 1980). This process involves a chain reaction via free radicals in the presence of molecular oxygen. The initiation generally involves the hemolytic abduction of a hydrogen atom from a fatty acid to give place to a free radical that quickly reacts with molecular oxygen to yield a peroxyl radical. This reaction is much more favorable in polyunsaturated fatty acids which can stabilize the unpaired electron within a group of conjugated double bonds (Chloe and Min, 2006). Peroxyl radicals propagate the reaction by abducting hydrogen atoms from fatty acids, with a parallel accumulation of fatty acid hydroperoxides. The termination reactions involve a reaction between intermediate radicals forming dimers and oligomers, which increments the viscosity of the oil. The accumulated hydroperoxide are unstable species that tend to break down into carbonilic fragments or react with other oxygenated species, giving way to ketones, epoxides, acids or ethers. This is called the secondary oxidation process and is responsible for the production of off-flavors in fats and oils. In the case of frying the reactions are accelerated by high temperatures, which also decrease the concentration of oxygen. In these conditions the oxygenated acyl chain can experiment cyclation, dehydration and breakage reactions, yielding harmful compounds like acrylamide or malondialdehyde (Kubow, 1992). The main initiators of autoxidation are metals or light in the presence of certain pigments. UV light can also promote oxidation though a different mechanism involving the activation of oxygen to the singlet form, which can directly attack the double bonds of fatty acids, and produce peroxyl radicals which are able to start the process of oxidation (Bradley and Min, 1992). The above-mentioned oxidation processes have been studied extensively in previous works on a large variety of vegetable oils. However, the oxidation caused by other different chemical agents in these oils is not so well known.

Ozone is an alotrophic form of oxygen consisting of 3 bonded oxygen atoms forming a bent molecule with resonant unsaturation. It is a very powerful oxidant, so it can react much faster than oxygen with any electron donor. It is naturally formed in the top layers of the atmosphere and can be easily 
produced in a corona discharge tube (Pietsch and Gibalov, 1998). Therefore, it is used as an oxidizing agent in synthetic chemistry, deodorization, bleaching and depuration of air and water (Kim et al., 1999; Guzel-Seydim et al., 2004). Ozone reacts with double bonds forming 1,2,3-trioxolanes or molozonides (Figure 1; Bailey, 1978). Molozonides are unstable and those synthesized in aprotic media tend to rearrange to the more stable Crieggerozonides through a mechanism involving the formation of a carbonyl oxide. Nevertheless, in the presence of protic solvents or water the carbonyl oxides can react and form different groups of derivatives. In the case of water, it would yield a carbonyl fragment and a terminal hydroxyl-hydroperoxide (Figure 1; Bailey, 1978). Studies on these compounds show that they are formed in living tissues in contact with ozone and are responsible for the cytotoxic effect of this gas (Santrock et al., 1992; Devlin et al., 1994). In this regard, hydroxyl-hydroperoxides display high biological activity and are a source of hydrogen peroxide through decomposition to a carbonyl derivative (Figure 1). Nevertheless, ozonides can also decompose into two carbonyl fragments, a reaction that is widely used in the degradative characterization of organic compounds (Thomas et al., 2007). Vegetable oils react with ozone easily, making the peroxide index increase at high rates. The amount of ozone that oils are able to incorporate depends on the degree of unsaturation of their fatty acids. Ozonized vegetable oils have applications in dermatology and cosmetics, as they display a well-known disinfectant and healing effect (Sechi et al., 2001;
Skalska et al., 2009; Valacchi et al., 2013; Serio et al., 2017). Nevertheless, the chemical characterization of ozonized vegetable oils is difficult due the large variety of oxygenated species they can contain. Moreover, the presence of highly oxidizing species can also induce the initiation of autoxidative processes, which can further increase the complexity of the oil composition (Díaz et al., 2005; 2006). In the present work the ozone absorption rate of different sunflower oils was studied, including common sunflower, high oleic sunflower (Garcés et al., 1989) and sunflower oils which display high levels of saturated palmitic (Fernández-Martínez et al., 1997) and stearic acids (Fernández-Moya et al., 2005). These oils were extracted from mutant sunflower lines developed to produce oils with different physical properties and oxidative stability. The kinetics of oxidation were completed with the analysis of fatty acids, which showed the species which were resistant to the oxidative attack. Spectrometric analysis by FT-IR supplied information about the nature of the new species formed. The mechanism of the reaction and the secondary reactions that took place during the oxidation of these oils are discussed according to the results obtained.

\section{MATERIALS AND METHODS}

\subsection{Oil ozonization and peroxide monitoring}

Four sunflower oils were ozonized: common sunflower from Borges Co. (Spain), and high oleic sunflower, high stearic-high oleic sunflower and high

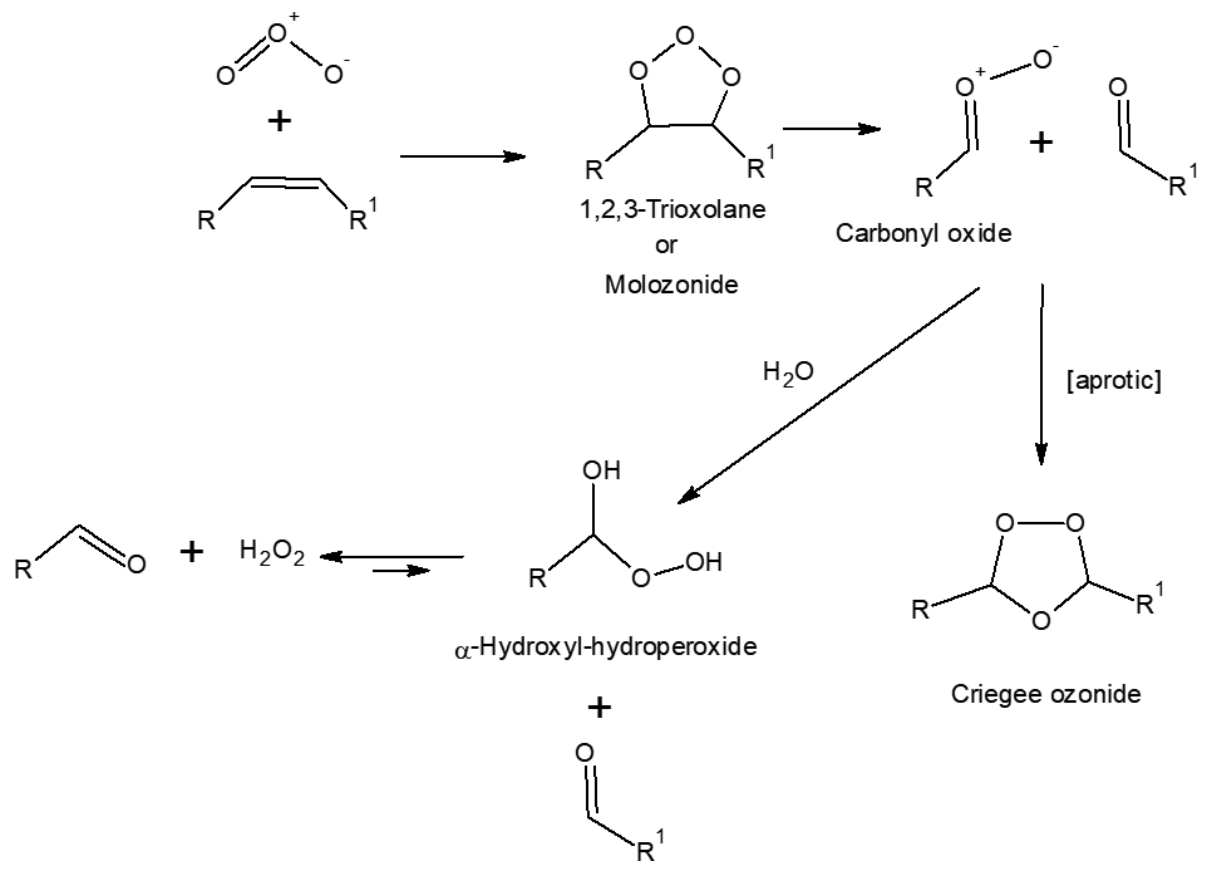

FIGURE 1. General scheme of the reactions involved in the ozonation of fatty acids in different media. Bailey (1978). 
palmitic-high oleic sunflower supplied by Instituto de la Grasa (Spain). The respective sunflower oil $(100 \mathrm{~mL})$ was placed in a jacketed bubbling reactor at a controlled temperature of $25 \pm 0.1^{\circ} \mathrm{C}$. A mixture of $\mathrm{O}_{3} / \mathrm{O}_{2}$ was introduced into the reactor at a flow rate of $30 \mathrm{~L} / \mathrm{h}$ during the reaction time $(2.75 \mathrm{~h})$. Samples were taken every 55 minutes corresponding to ozone mean doses of $0.45 ; 0.90$; and $1.33 \mathrm{~mol}$ of ozone per liter of oil. The ozone was generated in an AQOZO ozone generator (Havana, Cuba) and its concentration was determined by measuring the absorbance at $254 \mathrm{~nm}$ in an Ultraspec III spectrophotometer (Pharmacia LKB, Uppsala, Sweden). Every 5 minutes the ozone concentration was measured at the exit of the reactor. Three ozonation processes were carried out for each sunflower oil studied.

The peroxide value (PV) was measured following the protocol established by Martinez-Téllez et al., (2006). In this protocol $0.5 \mathrm{~g}$ of oil reacted with $0.5 \mathrm{~mL}$ saturated $\mathrm{KI}$ in $30 \mathrm{~mL}$ acetic acid/chloroform $3: 2$ in the dark for $24 \mathrm{~h}$. Then, a volume of $30 \mathrm{~mL}$ of distilled water was added and the mixture was titrated with $0.01 \mathrm{M}$ sodium thiosulphate. The PV was expressed as milli-equivalents of active oxygen per $\mathrm{kg}$ of sample.

\subsection{Analysis of fatty acid methyl esters}

Briefly, the oil was trans-esterified to its corresponding methyl esters by treating $5 \mu \mathrm{g}$ of sample with $1.5 \mathrm{~mL}$ methanol/toluene/sulfuric acid (88/10/2; $\mathrm{v} / \mathrm{v} / \mathrm{v}$ ) for 1 hour at $80^{\circ} \mathrm{C}$. The resulting methyl esters were then extracted with $1 \mathrm{~mL}$ of heptane and analyzed by gas chromatography. The GC system was similar to that reported by TAG analysis but equipped with a Supelco SP-2380 fused silica capillary column (30 m length; $0.25 \mathrm{~mm}$ i.d.; $0.20 \mu \mathrm{m}$ film thickness: Bellefonte, PA). The injection temperature was $200^{\circ} \mathrm{C}$, and hydrogen was used as carrier gas at a rate of $28 \mathrm{~cm} / \mathrm{s}$. The oven temperature was set at $170{ }^{\circ} \mathrm{C}$ and the FID detector operated at $200{ }^{\circ} \mathrm{C}$. Fatty acid methyl esters were identified according to their retentions times, which were compared with those from commercial standards. Oxidation fragments were identified by GC-MS as methanol ketals or diketals of carbonilic moieties. Composition was calculated from peak integration data.

\subsection{ATR-FTIR spectroscopy}

Spectral data were collected on a Bruker Vertex 70 FTIR spectrometer and a Bruker Equinox 55 spectrometer both equipped with a DGTS detector (Bruker Optics, Ettlingen, Germany) and a Specac (Orpington, U.K.) ZnSe attenuated total reflectance (ATR) crystal with 6 bounces. Each spectrum was recorded at room temperature over the region of $4000-600 \mathrm{~cm}^{-1}$ using 50 scans at a resolution of $4 \mathrm{~cm}^{-1}$. Before each analysis, the background spectrum was taken with the empty ATR crystal and stored in the computer. Each sample $(240 \mu \mathrm{L})$ was spread uniformly through the ATR crystal and analyzed in duplicate. Between samples, the ATR crystal was thoroughly cleaned and dried with hexane and alcohol and its cleanliness verified spectrally. The spectra were manipulated with OPUS version 4.0 (Bruker Optics, Ettlingen, Germany), and the results were exported by the Unscrambler X 10.3 (CAMO Software AS. Oslo, Norway) for further study.

\subsection{Statistical treatment}

The values of different magnitudes represented the average of three independent determinations plus or minus standard deviation.

\section{RESULTS AND DISCUSSION}

\subsection{Courses of oil ozonization}

Four different sunflower oils were used in the present work. The common sunflower oil displayed a content of $62 \%$ linoleic acid and $30 \%$ oleic acid (Table 1). The high oleic oil displayed around $84 \%$ oleic acid with much lower levels of linoleic acid $(5 \%)$. The other two oils displayed higher levels of stearic and palmitic acids in a high oleic background. The former oil contained $16 \%$ stearic acid with high levels of oleic $(71 \%)$ and a low content of linoleic

TABLE 1. Fatty acid compositions of the different sunflower oils used in this study. (Data are expressed in mole per cent).

\begin{tabular}{lrrrrrrrc}
\hline & $\mathbf{1 6 : 0}$ & $\mathbf{1 6 : 1}$ & $\mathbf{1 8 : 0}$ & $\mathbf{1 8 : 1}$ & $\mathbf{1 8 : \mathbf { 1 } ^ { \mathbf { 4 1 } }}$ & $\mathbf{1 8 : 2}$ & $\mathbf{2 0 : 0}$ & $\mathbf{2 2 : 0}$ \\
\hline Common & 6.2 & 0.0 & 3.7 & 25.7 & 0.6 & 62.6 & 0.3 & 0.8 \\
High oleic & 5.4 & 0.5 & 3.2 & 83.8 & 0.8 & 5.0 & 0.3 & 1.0 \\
High stearic & 5.1 & 0.0 & 16.2 & 70.8 & 0.3 & 4.6 & 1.2 & 1.8 \\
High palmitic & 27.3 & 7.8 & 2.2 & 54.3 & 4.7 & 2.0 & 0.5 & 1.3 \\
\hline
\end{tabular}

Data in the table correspond to the average of 3 technical replicates. The standard deviation in each percentage was below $5 \%$ in all cases. Fatty acids under $0.2 \%$ were not quantified. 
(4.6\%), whereas the later contained as much as $27 \%$ palmitic acid. This later oil also displayed high levels of oleic (54\%) and differed from the other ones in its content in the n-7 fatty acids palmitoleic $(16: 1)$ and asclepic $\left(18: 1^{\Delta 11}\right)$. Thus, these fatty acids were in trace amounts in the other oils studied, but accounted for as much as $7.8 \%$ and $4.7 \%$, respectively, in the high palmitic oil. These oils were treated with increasing amounts of ozone, which was produced in a generator at a constant flow and was dispersed into the oil at a constant temperature. The progress of the reaction was monitored by taking samples of the oil and measuring its peroxide value. Water was also included in these reactions since it is usually included at the industrial scale for the preparation of ozonized oils to promote the formation of hydroxylhydroperoxides, which display higher germicidal activity than Criegge ozonides. The oxidation of the oils investigated with ozone displayed a linear pattern in all cases (Figure 2), with little or no difference

A

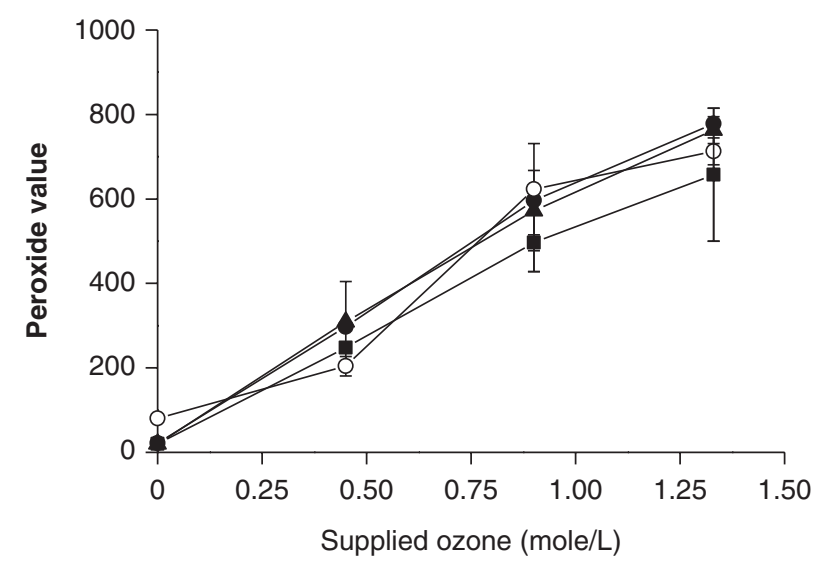

B

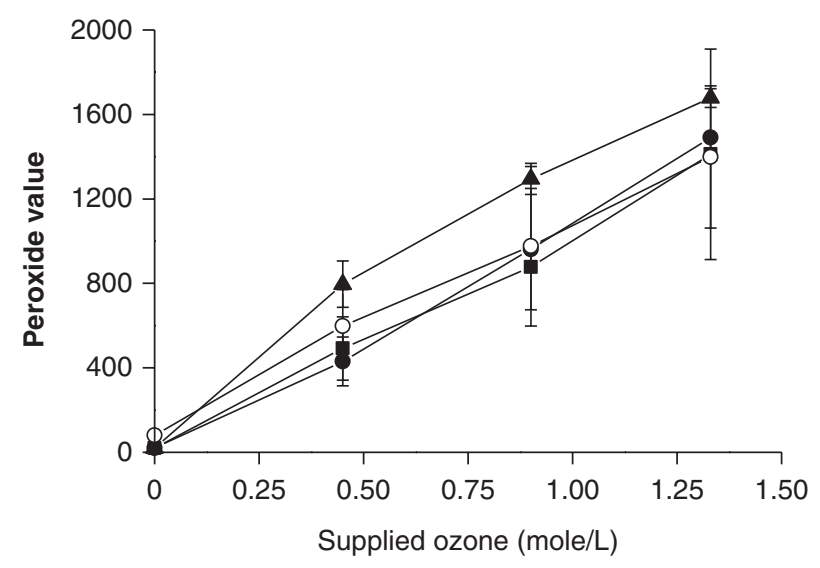

FIGURE 2. Courses of ozonation of different sunflower oils. Data represent the increment in peroxide value against the supplied ozone in the presence of $5 \%$ water (A) or $10 \%$ water (B). Common sunflower (-m-), high oleic sunflower (-•-), High stearic sunflower (- $\mathbf{\Delta -}$ ) and high palmitic sunflower (-o-) oils were used as substrates. Data represent average data from three determinations plus or minus standard deviation. among the different oils used as substrates despite their different fatty acid compositions. The rates of oxidation were dependent on the initial amount of water. Thus, the increase in water content from $5 \%$ to $10 \%$ doubled the oxidation rates of the different oils. The data from the oxidation course indicated that ozone, being an oxidant much stronger than $\mathrm{O}_{2}$, reacted quickly with the TAGs in the different oils in such a way that the rate of the chemical reaction or the fatty acid compositions of the oils were neither limiting nor determinant. Therefore, the rate of oxidation was mainly determined by the diffusion of the reactant into the oils. The presence of water in percentages of $5 \%$ and $10 \%$ seemed to increase the solubility and transference of ozone into the system, increasing the diffusion rates of the reactant into the oil. Nevertheless, more research is necessary to confirm this point. The acidity values of the final ozonized oils were also determined in these courses (Figure 3). Common sunflower oil displayed the highest increase in acidity, and reached values of 6 and 9 at the end of the two ozonization courses. The other oils also displayed increments in their acidity values but stayed in a lower range (2 to 5). The addition of water enhanced the final acidity of the ozonized oils. The increase in the acidity values through ozonization is usually due to the oxidation of carbonyl moieties by the excess of ozone in the medium (Santrock et al., 1992). Thus, the increment in this parameter was compatible with the higher rates of oxidation with greater additions of water. Moreover, the data suggested that carbonyls produced from the common sunflower, mainly hexanal and nonenal coming from linoleic acid, were more easily oxidized than those from the other oil, which mainly consisted of nonanal produced from oleic acid.

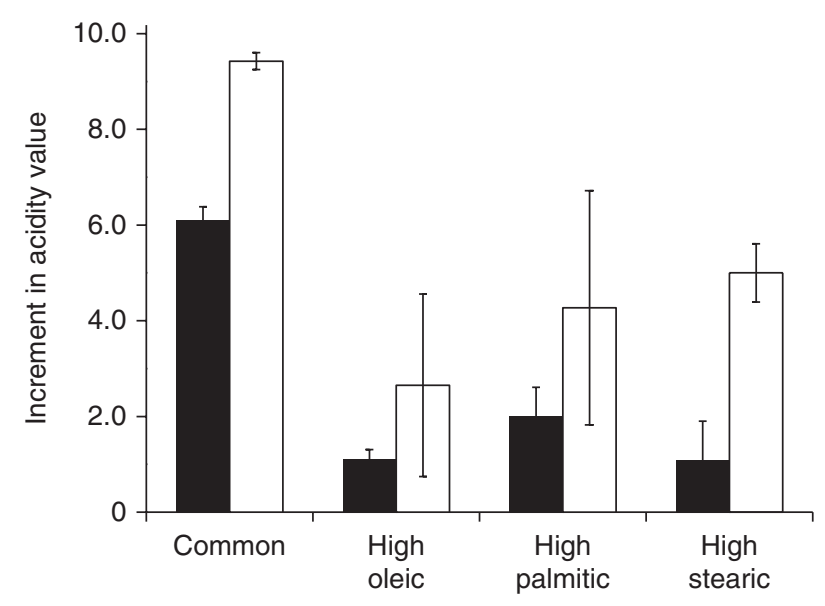

Figure 3. Increase in acidity values after ozonation of different sunflower oils. Data correspond to final products from the courses depicted in Figure 2 with 5\% water (black bars) or

$10 \%$ water (white bars). Data represent the average of three determinations plus or minus standard deviation. 
The profiles of ozone oxidation of sunflower oils were very different from those reported for autoxidation. Thus, the rates of autoxidation of these oils were studied in a previous work using the Rancimat system, in which the induction time of the oxidation process in certain conditions (temperatures around $100{ }^{\circ} \mathrm{C}$ and $\mathrm{O}_{2}$ bubbling) is measured according to the formation of volatiles which alter water conductivity (Márquez-Ruiz et al., 1999). This study indicated that the rates of autoxidation varied substantially among the different oils, with common sunflower oxidizing much faster than high oleic sunflower, which oxidized faster than the highly saturated oils, Moreover, the kinetics of oxidation displayed the sigmoidal curves typical of the chain reaction processes depicted in the introduction. The ozonization reaction was not dependent on the fatty acid composition in the first stages of the process, which were those observed in this study. This was because it depended on the presence of double bonds in the oil, which were always in excess at the beginning. Once the reaction advanced, the number of double bonds available for ozone attack decreased and so the rates of oxidation progressively dropped until ozonization was complete. Nevertheless, that point was not reached in the present study for any of the oils used as substrate.

\subsection{Fatty acid composition}

The most direct way to study the alteration experimented by oils during the process of ozonization is to study the fatty acid composition of the oils at different stages of that reaction. The fatty acid composition of oils is usually measured by transesterification of the acyl moieties from TAGs to methanol, followed by the analysis of resulting fatty acid methyl esters (FAMES) by GLC. Thus, ozonized oil samples were transmethylated in an acidic medium. The resulting GLC records displayed important differences due to ozonization when compared with those from the oil substrates. They displayed a series of unidentified peaks in the range of low C8-C12 fatty acids and they had to be identified by means of GC/MS. Most of the unidentified peaks corresponded to C9 carbonyls and carbonyl derivatives formed from 9,10-mol ozonide derivatives from oleic or linoleic fatty acids (Bailey, 1978). Therefore the products found were nonanal, 2-nonenal and their corresponding ketals and diketals with methanol. Nonanoic and 2-nonenoic fatty acids were also present, which were formed through the oxidation of carbonyls by ozone and were compatible with the increment in acidity values in Figure 3. These compounds were quantified together as C9 terminal derivatives (Figure 4). Moreover, other series of oxidation derivatives found corresponded to the complementary $\mathrm{C} 9$ or $\mathrm{C} 12$ oxoacids resulting from ozonization breakage. These data showed that the ozonides and peroxides produced during the oxidation reaction split during the derivatization and analysis of the samples. The C6 fragments resulting from the ozonization of the delta 12,13 double bond of linoleic acid were not present because they are volatile compounds that probably coincide with the beginning of the GC analysis. Furthermore, all the fatty acids present in the initial oil were also found in the ozonized samples, although their proportions changed after ozonization (Figure 2). The fatty acids present in the samples and analyzed as their FAMEs were unchanged after the reaction, and provided information regarding the specificity of the oxidative attack of ozone on different oils. The results in figure 3 display the fatty acid composition of the series of ozonized oils obtained by adding $10 \%$ water in the reaction mixture and are represented by series B in Figure 1. Those in series A display a similar pattern (data not shown). Common sunflower, which was rich in linoleic acid (Table 1) produced lower amounts of C9-terminal derivatives and similar amounts of $\mathrm{C} 9$ and $\mathrm{C} 12$ oxoacid fragments. The proportion of C9 against C12 fragments was similar at the beginning of the course and increased with ozonization time until C9 oxoacids almost doubled the $\mathrm{C} 12$ ones, indicating a preference of ozone for attacking the more external delta 12 bonds of linoleic acid at shorter reaction times. This specificity declined when the reaction advanced (Figure 2A). According to the untransformed FAME species, linoleic acid displayed the most rapid decay in proportions which decreased substantially throughout the whole course. The decay of oleic acid was slower and tended to be faster at a longer reaction time. This result was expected due to the fact that linoleic acid was the most abundant fatty acid in this oil and it displayed two double bond targets that could be attacked by ozone. Once there was less linoleate available, the oxidation of oleic acid started to increase. The decrease in oleic and linoleic acid was compensated by the increase in carbonyl compounds and saturated fatty acids, which increased their proportions throughout the whole course. The results obtained from the high oleic oil displayed significant decreases in oleic acid throughout the whole course (Figure 2B), which decreased from initial values of $83 \%$ to $40 \%$ at the end of the experiment, with a concomitant increase in C9 terminal products, mainly nonanoic acid, nonanal and derivatives. It is worth mentioning that the content of terminal compounds was higher this time than those coming from internal fragments (oxoacids). The possible cause of this could be a further degradation of these compounds throughout the process of oxidation caused by secondary reactions. The content of 18:2 in the oil also decreased throughout the course and was close to the detection limit at the end of the experiment. High oleic oil contains low 
A

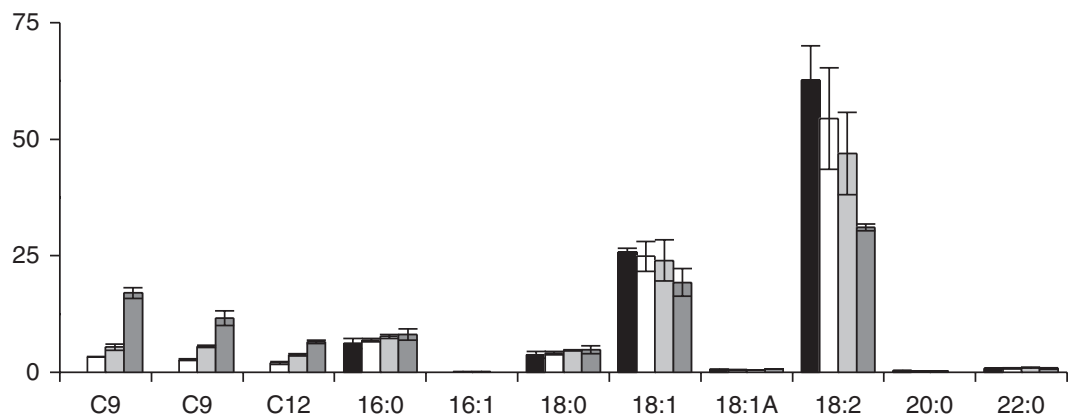

Terminal Oxoacid Oxoacid

B

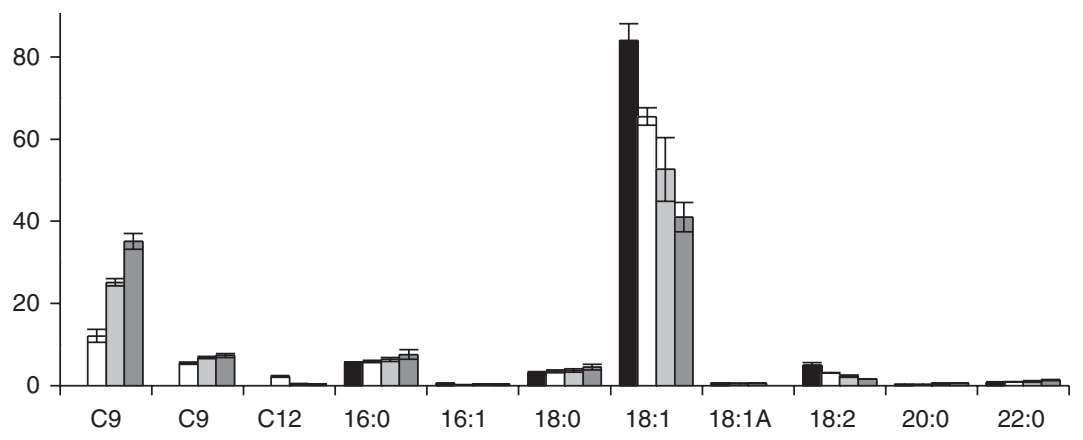

C

Terminal Oxoacid Oxoacid

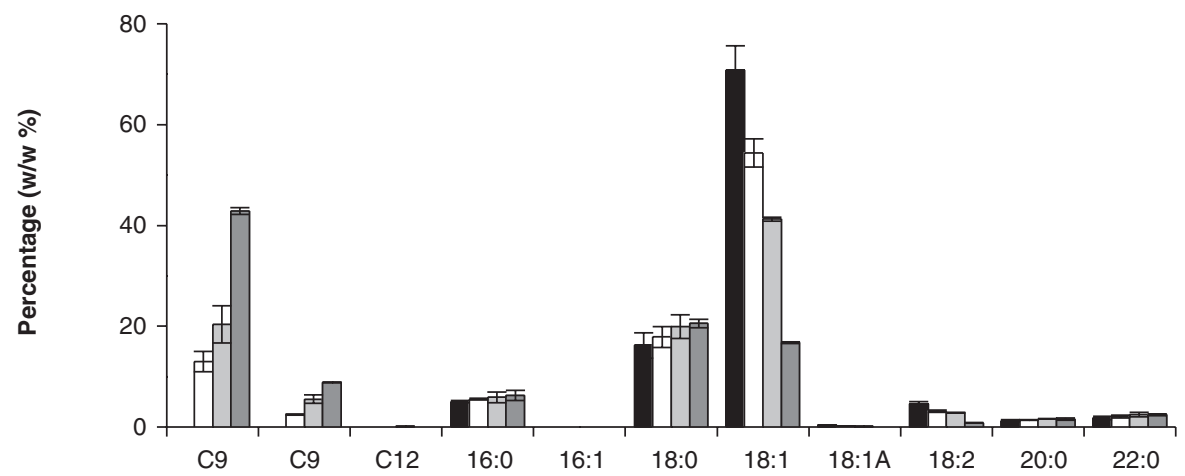

D

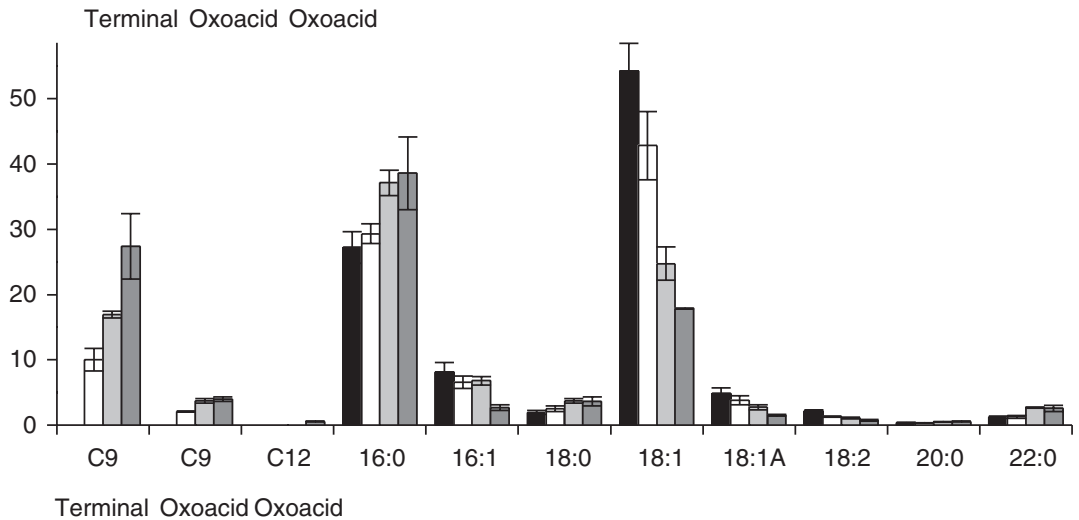

FIGURE 4. Fatty acid and carbonyl compound composition of different sunflower oils during the course of ozonation in the presence of $10 \%$ water. Data correspond to initial oils (Black bars), $50 \mathrm{mmol}$ ozone applied (white bars), $100 \mathrm{mmol}$ ozone applied (light grey bars) and $150 \mathrm{mmol}$ ozone applied (dark grey bars). Common sunflower (A), high oleic sunflower (B), High stearic sunflower (C) and high palmitic sunflower (D) oils were used as substrates. Data represent the average data of three determinations plus or minus standard deviation. 
levels of saturated fatty acids, mainly 16:0 and 18:0 and traces of 20:0 and 22:0 that increase throughout oxidation.

The pattern of oxidation displayed by the high oleic oil was similar to those displayed by the highly saturated oils high stearic and high palmitic, although in those cases the decrease in oleic acid was more pronounced. Thus, in the case of the high stearic oil the content of oleic acid decreased from $70 \%$ to around $16 \%$, with a strong increase in the C9 terminal fragments. This indicated that a high percentage $(78 \%)$ of the oleic acid was peroxidated during the reaction, and was practically the only fatty acid to suffer the oxidative attack out of the small amount of linoleic acid that was almost completely oxidized. The high palmitic oil displayed a similar pattern, with the oleic acid undergoing a drastic decrease. This time other unsaturated fatty acids also experimented oxidation. They were palmitoleic and asclepic fatty acids (16:1 and 18:1A), which decreased in a proportion similar to oleic acid. It is remarkable that once ozonized these fatty acids did not produce two C9 fragments but a C7 external carbonyl or caboxilic fragment and a C9 inner one in the case of $16: 1$ and C7 and C11 moieties in the case of asclepic. Nevertheless, these compounds were in low proportion and were quantified together with C9 compounds.

According to these results we can conclude that ozone reacts with all unsaturated fatty acids present in the oil, which in this case were oleic and linoleic acid. The difference in reactivity between different fatty acids is given by the number of double bond targets they have. This constrasted with the autoxidation processes, where polyunsaturated fatty acids were oxidized much faster than monounsaturated ones because they are able to stabilize free radicals by conjugation (Frankel, 1980). Thus, the concentrations of these fatty acids determined the autoxidation rates in vegetable oils and were the most affected during the oxidation process.

\subsection{FT-IR spectroscopic study}

The analysis of FAMEs showed the fatty acids oxidized in the process of ozonization. However, the transmethylation and GC analysis of fatty acids destroyed the ozonides and peroxides present in the oxidized oils so the information obtained about the products in the process of ozonization was incomplete. Spectroscopic studies based on ${ }^{1} \mathrm{H}$ and ${ }^{13} \mathrm{C}$ NMR of ozonized sunflower oils have been published in previous works (Díaz et al., 2005 and 2006). These oils displayed signals corresponding to chemical shifts typical of olefinic carbon multiplets $(\delta=5.35$ $\mathrm{ppm}$ ) that decreased with the degree of ozonation, at the moment new proton species appeared which corresponded to Criegge ozonides $(\delta=5.15 \mathrm{ppm})$ and olefinic protons from hydroperoxides $(\delta=5.55 \mathrm{ppm})$.
Weak signals corresponding to carbonyl compounds $(\delta=9.63,9.74 \mathrm{ppm})$ also appeared along the course of ozonation. With regard to ${ }^{13} \mathrm{C}$ NMR, the results were in agreement with $1 \mathrm{H}$ NMR data, with signals corresponding to methynic carbons associated with ozonides and hydroperoxides at 104 to $122 \mathrm{ppm}$ and aldehyde carbons resonating at 199 to $203 \mathrm{ppm}$.

The use of the FT-IR spectroscopy allowed for determining the predominant functional groups in a given substrate, which would determine the chemical species that appeared in vegetable oils after the process of ozonization. In the present work we determined the FT-IR spectra of the initial oils used in ozonization and the ozonized oils resulting at the end of the process of ozonization described in the experimental section obtained by addition of $10 \%$ water in the oxidation medium. Initial oils displayed a similar spectrum, which is the one typically found for vegetable oils. However, in the spectra of the non-ozonized samples the band at $\left(3003-3009 \mathrm{~cm}^{-1}\right)$ assigned to the $\mathrm{C}-\mathrm{H}$ stretching vibration of the cis double bond $(-\mathrm{CH})$ revealed the fatty acid composition of the samples. The exact position of this band is dependent on the proportion of the fatty acids. Thus, the spectrum of common sunflower oil, with $62 \%$ linoleic acid and $20 \%$ oleic acid, presented the maximum of this band at $3008 \mathrm{~cm}^{-1}$, while the spectrum of high oleic sunflower, with $5 \%$ linoleic acid and $84 \%$ oleic acid, presented the maximum at $3003 \mathrm{~cm}^{-1}$. The spectra of high stearic sunflower oil and high palmitic sunflower oil, with $71 \%$ and $54 \%$ oleic acid, respectively, presented the maximum of this band at $3004 \mathrm{~cm}^{-1}$ (Figure 5). The spectra displayed two groups of strong vibrational bands (Figure $5 \mathrm{~A}$ to $\mathrm{D}$ ). The first one was found at $1750 \mathrm{~cm}^{-1}$ and corresponded to the ester group present in TAGs. Close to this band (1750-1690 $\left.\mathrm{cm}^{-1}\right)$ a weaker signal corresponding to aldehydes or free carboxylic acids was found. A weaker signal produced by the $\mathrm{CH}_{2}$ group was also found at $1450 \mathrm{~cm}^{-1}$. The second group of signals was around $3000-2750 \mathrm{~cm}^{-1}$ and corresponded to carbon-hydrogen bonds and the carbon-to-carbon double bonds $\left(3000 \mathrm{~cm}^{-1}\right)$. In the area around $3500 \mathrm{~cm}^{-1}$ weak signals corresponded to hydroxyl groups and the $\mathrm{C}$ to oxygen overtone from ester groups. The fingerprint region embraced from 600 to $1400 \mathrm{~cm}^{-1}$. In the spectra of the ozonized oils the band assigned to the $\mathrm{C}=\mathrm{O}$ stretching vibrations of the ester group of triglycerides $\left(1750 \mathrm{~cm}^{-1}\right)$ presented a widening to lower wavenumbers probably because the concentration of aldehydes and free fatty acids increased during the ozonide analysis (Figure 4). In the region of the fingerprint, the band at $1099 \mathrm{~cm}^{-1}$ presented a higher intensity in the spectra of ozonized oils compared to the spectra of the non-ozonized oil. This band was assigned to a $\mathrm{C}-\mathrm{O}$ stretching vibration, the increment in this band showed the formation of oxidized compounds that this functional group contained (Figure 4). However, the most remarkable 

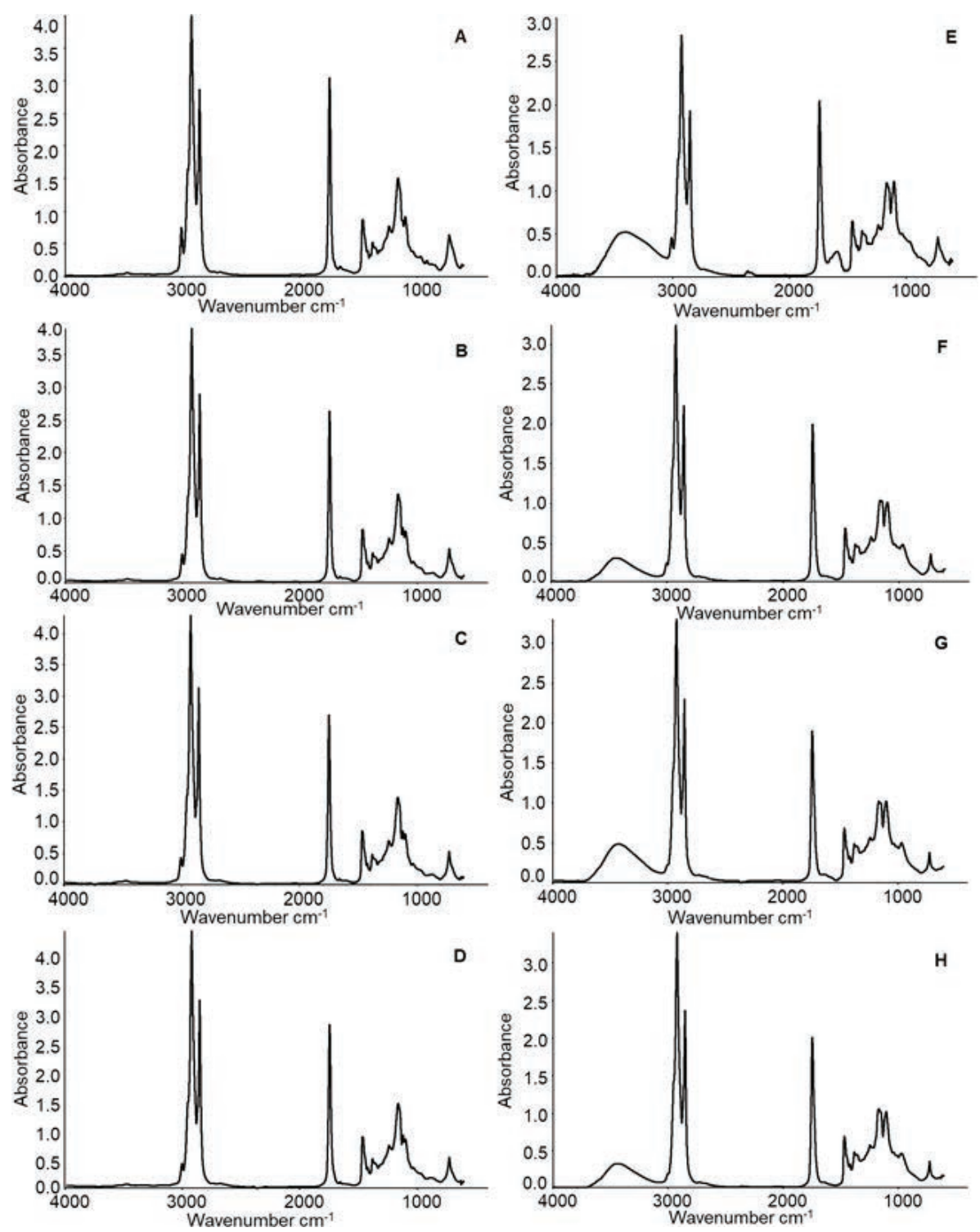

FIGURE 5. FT-IR spectra of common sunflower, high oleic sunflower, High stearic sunflower and high palmitic sunflower oils before (A, B, C and D, respectively) and after (E, F, G and H, respectively) ozonation. Data correspond to final products from the courses depicted in Figure 2 with $10 \%$ water.

difference found in the spectra of ozonized oils in comparison with the spectra of non-ozonized oils was a large broad peak in the interval from 3100 to $3700 \mathrm{~cm}^{-1}$. This signal was produced by the hydroperoxide group through the stretching of the $\mathrm{O}-\mathrm{H}$ bond. The peak was also expanded to the area of wavelength higher than $3500 \mathrm{~cm}^{-1}$, which could indicate the presence of hydroxyl groups. These data were in good agreement with previous NMR results, which pointed to the presence of hydroperoxydes and carbonyl compounds in these oils (Díaz et al., 2005 and 2006). Moreover, the FT-IR records obtained in this work revealed that the water added to the reaction media reacted with molozonides resulting from the oxidative attack of ozone on the double bonds from unsaturated fatty acids making way for alphahydroxyl hydroperoxides, as shown in Figure 1. This would explain the formation of such a large absorption peak in the area from 3750 to $3200 \mathrm{~cm}^{-1}$, to which the stretching of $\mathrm{O}-\mathrm{H}$ bonds from hydroxyl and hydroperoxyde groups would contribute.

\section{CONCLUSIONS}

In the present work, we studied the oxidation of different sunflower oils by the application of ozone. These oils displayed different fatty acid compositions, including the common oil, rich in linoleic, 
high oleic oil and oils with high contents of saturated fatty acids (palmitic and stearic) in a high oleic background. The courses of oxidation of these oils displayed linear increments in the peroxide values for all the oils, indicating that the reaction rates were not limiting and that a fast incorporation of the ozone into the double bonds of fatty acids took place. The kinetics and oxidation pattern were very different to those found in autoxidation processes. Moreover, the ozonation courses took place in the presence of water to favor the formation of active hydroxyl-hydroperoxides. The presence of higher amounts of water favored oil oxidation probably because it increased the amount of available ozone substrate. The resulting ozonized oils were characterized in terms of fatty acid composition, which revealed the fatty acids that received ozonation. In the case of common sunflower, the higher rates of ozonation were supported by linoleic acid which decayed quickly during the course, although to a lesser extension oleic acid. In the remaining oils the ozonation reaction took place mainly in oleic acid, which was by far the most abundant unsaturated fatty acid. The content of non-transformed saturated fatty acid increased steadily throughout the oxidation course. FT-IR studies on the ozonized oils showed a large vibrational band in the interval from 3100 to $3700 \mathrm{~cm}^{-1}$, compatible with the formation of hydroxyl-hydroperoxides as major products of the oxidation reaction, which was compatible with the experimental conditions applied.

\section{ACKNOWLEDGEMENTS}

This work was funded by the project ICOOPCOOPB20153 from the Consejo Superior de Investigaciones Científicas (CSIC).

\section{REFERENCES}

Bailey PS. Ozonation in organic chemistry. Volume I. Olefinic compounds. (New York, Academic press, 1978). ISBN: 9780323157483.

Bradley DG, Min DB. 1992. Singlet oxygen oxidation of foods. Critical Rev. Food Sci. Nutrition 31, 211-236. https://doi. org/10.1080/10408399209527570

Choe E, Min DB. 2006. Mechanisms and factors for edible oil oxidation. Comprehensive Rev. Food Sci. Food safety 5 , 169-186. https://doi.org/10.1111/j.1541-4337.2006.00009.x

Crapiste, GH, Brevedan MI, Carelli AA. 1999. Oxidation of sunflower oil during storage. J. Am. Oil Chem. Soc.76, 1437-1444. https://doi.org/10.1007/s11746-999-0181-5

Devlin RB, McKinnon KP, Noah T, Becker S, Koren HS. 1994. Ozone-induced release of cytokines and fibronectin by alveolar macrophages and airway epithelial cells. Am. J. Physiol.-Lung Cellular Mol. Physiol. 266, L612-L619. https://doi.org/10.1152/ajplung.1994.266.6.L612

Díaz MF, Gavín-Sazatornil JA, Ledea OE, Hernández F, Alaiz M, Garcés R. 2005. Spectroscopic characterization of ozonated sunflower oil. Ozone Sci. Eng. 27, 247-253. https://doi. org/10.1080/01919510590945822
Díaz MF, Gavín JA, Gómez M, Curtielles V, Hernández F. 2006. Study of ozonated sunflower oil using $1 \mathrm{H}$ NMR and microbiological analysis. Ozone Sci. Eng. 28, 59-63. https://doi.org/10.1080/01919510500479239

Fernández-Martínez JM, Mancha M, Osorio J, Garcés R. 1997. Sunflower mutant containing high levels of palmitic acid in high oleic background. Euphytica 97, 113-116. https:// doi.org/10.1023/A:1003045726610

Fernández-Moya V, Martínez-Force E, Garcés R. 2005. Oils from improved high stearic acid sunflower seeds. J. Agric. Food Chem. 53, 5326-5330. https://doi.org/10.1021/jf0503412

Frankel EN. 1980. Lipid oxidation. Prog. Lipid Res. 19, 1-22. https://doi.org/10.1016/0163-7827(80)90006-5

Garcés R, García JM, Mancha M. 1989. Lipid characterization in seeds of a high oleic acid sunflower mutant. Phytochem. 28, 2597-2600. https://doi.org/10.1016/S0031-9422(00)98047-6

Gunstone FD. 2011. Vegetable Oils in Food Technology: Composition, Properties and Uses. Blackwell Publishing, Oxford, UK. ISBN 1-84127-331-7

Guzel-Seydim ZB, Greene AK, Seydim AC. 2004. Use of ozone in the food industry. LWT-Food Sci. Technol. 37, 453-460. https://doi.org/10.1016/j.lwt.2003.10.014

Kim JG, Yousef AE, Dave S. 1999. Application of ozone for enhancing the microbiological safety and quality of foods: a review. J. Food Protection 62, 1071-1087. https://doi. org/10.4315/0362-028X-62.9.1071

Kubow S. 1992. Routes of formation and toxic consequences of lipid oxidation products in foods. Free Radical Biol. Med. 12, 63-81. https://doi.org/10.1016/0891-5849(92)90059-P

Márquez-Ruiz G, Garcés R, León-Camacho M, Mancha M. 1999. Thermoxidative stability of triacylglycerols from mutant sunflower seeds. J. Am. Oil Chem. Soc. 76, 1169-1174. https://doi.org/10.1007/s11746-999-0091-6

Martínez-Téllez G, Ledea Lozano O, Díaz-Gómez MF. 2006. Measurement of peroxidic species in ozonized sunflower oil. Ozone Sci. Eng. 28, 181-185. https://doi.org/10.1080/ 01919510600689356

Pietsch GJ, Gibalov VI. 1998. Dielectric barrier discharges and ozone synthesis. Pure Applied Chem. 70, 1169-1174. https://doi.org/10.1351/pac199870061169

Salas JJ, Bootello MA, Garcés R. 2015. Food Uses of Sunflower Oils. In: Sunflower Chemistry, Production, Processing, and Utilization. Salas JJ, Enrique MF and Dunford NT (Eds.) AOCS Press, Champaign, IL (pp. 441-464). https://doi. org/10.1016/B978-1-893997-94-3.50020-9

Santrock J, Gorski RA, O'Gara JF. 1992. Products and mechanism of the reaction of ozone with phospholipids in unilamellar phospholipid vesicles. Chem. Res. Toxicol. 5, 134-141. https://doi.org/10.1021/tx00025a023

Sechi LA, Lezcano I, Nunez N, Espim M, Duprè I, Pinna A, Molicotti P, Fadda G, Zanetti S. 2001. Antibacterial activity of ozonized sunflower oil (Oleozon). J. Appl. Microbiol. 90, 279-284. https://doi.org/10.1046/j.13652672.2001.01235.x

Serio F, Pizzolante G, Cozzolino G, D'Alba M, Bagordo F, De Giorgi M, Grassi T, Idolo A, Guido M, De Donno A. 2017. A new formulation based on ozonated sunflower seed oil: in vitro antibacterial and safety evaluation. Ozone Sci. Eng. 39, 139-147. https://doi.org/10.1080/019 19512.2016.1272405

Skalska K, Ledakowicz S, Perkowski J, Sencio B. 2009. Germicidal properties of ozonated sunflower oil. Ozone Sci. Eng. 31, 232-237. https://doi.org/10.1080/01919510902838669

Thomas MC, Mitchell TW, Harman DG, Deeley JM, Murphy RC, Blanksby SJ. 2007. Elucidation of double bond position in unsaturated lipids by ozone electrospray ionization mass spectrometry. Anal. Chem. 79, 5013-5022. https://doi. org/10.1021/ac0702185

Valacchi G, Zanardi I, Lim Y, Belmonte G, Miracco C, Sticozzi C. Bocci V, Travagli V. 2013. Ozonated oils as functional dermatological matrices: Effects on the wound healing process using SKH1 mice. Int. J. Pharmaceutics 458, 65-73. https://doi.org/10.1016/j.ijpharm.2013.09.039 